\title{
Timothy Snyder. 2015. Tierra negra. El Holocausto como historia y advertencia. Barcelona: Galaxia Gutenberg, 528 p.
}

Timothy Snyder és conegut, en el mercat català (i espanyol), per dues aparicions bibliogràfiques recents: per una banda, la recopilació que va fer de les converses a mb Tony Judt convertides en el llibre Pensar el segle Xx (Barcelona: La Magrana, 2012), que fa la funció de testament intellectual de l'historiador britànic, desaparegut l'any 2010. Per l'altra, la traducció castellana que va donar lloc a Tierras de sangre. Europa entre Hitlery Stalin (Barcelona: Galaxia Gutenberg, 2011), un llibre esplèndid sobre les matances perpretades pels règims estalinista i nazi en els territoris de l'est d'Europa (i l'oest de la URSS) durant la dècada dels trenta i els anys de la Segona Guerra Mundial.

A Tierras de sangre, Snyder no es limitava a fer inventari de matances de tota mena, que culminarien en l'extermini en massa dels camps nazis. Hi explorava els mecanismes de generació de terror, persecució i violència dels règims polítics sobre les seves poblacions (no només dels jueus) i el pes de les ideologies, a fi de construir una narració que, més enllà de l'horror que destillava en les seves descripcions i interpretacions, portava al centre del segle $\mathrm{xx}$ certs fenòmens que, més tard, es generalitzarien en altres territoris del planeta. Aquell llibre, però, també deixava un altre assumpte inquietant sobre la taula del lector: tot allò havia succeït a Europa, el continent modern i civilitzat, el bressol del catolicisme, el protestantisme i la Illustració.

Ara, a Tierra negra, repeteix l'operació de construir una narració històrica, però en varia el punt de mira. Snyder enfoca l'anàlisi en la Shoa, els seus antecedents i la seva realització, en un escenari semblant al de Tierras de sangre: la gran i sagnant marxa nazi cap a l'Est, a la conquesta de l'espai vital (el lebensraum) en terres poloneses, bàltiques, ucraïneses, etc. Dins d'aquest marc, la recerca se centra en uns protagonistes principals. Per una banda, els jueus de tots els territoris amenaçats, començant pels alemanys, i la seva difícil relació de convivència amb els estats que, teòricament, els havien d'emparar. Per l'altra, els perseguidors, els perpretadors de les matances, la deportació massiva, les persecucions en totes les escales imaginables. De fet, en el fons ens vol parlar de la dimensió europea de l'antisemitisme i la seva traducció assassina. Quan explica que la mateixa tarda de l'Anschluss, és a dir, poques hores després que l'Estat austríac deixés d'existir, ciu- 
tadans exemplars fins aleshores ja estaven manant els seus veïns jueus que freguessin les voreres dels carrers i altres humiliacions, ens transmet una idea poderosa: la Shoa i els seus antecedents van ser un assumpte europeu.

No és una idea nova, però la virtut del llibre és la voluntat de l'autor de donar una nova volada a unes qüestions que han consumit milers de pàgines i hores de documentals, i que s'han incrustat en la consciència contemporània d'una manera indefugible. Sortosament, Snyder esquiva el món, cada vegada més estrany, dels genocides studies, i ens ofereix un treball històric i historiogràfic sòlid. Com és sabut, els genocides studies s'han convertit en una mena d'indústria bibliogràfica, en què hi ha anat a caure de tot: des del memorialisme i la psicologia social, fins a l'antropologia, la filosofia i la literatura, passant per una mica d'historiografia. Cada vegada més allunyats dels orígens científics al voltant del món dels camps d'extermini i els genocidis, s'han convertit en una mena de gènere literari amb vida pròpia, propici a tota mena d'excessos. Algunes patinades d'historiadors com Christian Gerlach (aplaudit entusiàsticament per historiadors espanyols, que es vanten d'haver descobert en la repressió franquista una forma original de genocidi), els han portat a un carreró sense gaires sortides (o no cap).

Snyder s'estalvia d'entrar en aquest terreny i centra la seva anàlisi en qüestions més àmplies i complexes: una relectura força interessant de les tesis biologistes, antisemites i racistes d'Adolf Hitler; el paper, interessantíssim, de Carl Schmitt a l'hora de donar una pàtina de respectabilitat acadèmica i jurídica als projectes exterministes i expansionistes nazis; els continguts precisos de les teories de l'«espai vital»; entre altres.

Per altra banda, l'autor beu contínuament (i no se n'amaga) del seu treball anterior, Tierras de sangre, que ja trepitjava una part del terreny que ara analitza. Ho fa estalviant-nos de retornar als paràmetres de la justament desacreditada geopolítica (una pseudodisciplina paracientífica que, en l'actualitat, s'ha tornat a posar de moda, sobretot entre periodistes amb vocació d'intellectuals). Certament, en el llibre hi ha uns quants mapes per situar el lector; però no comet l'error de començar a teoritzar sobre línies de força, expansions naturals (o no) i altres elements que tant van agradar als practicants d'aquesta pseudodisciplina en els anys quaranta del segle passat.

El que ens posa davant dels ulls és un immens espai geogràfic, que va de Polònia a Ucraïna, passant per Bielorrússia i els països bàltics, escenari 
principal de les ambicions expansives de l'Alemanya nazi després d'haver liquidat Àustria i Txecoslovàquia. En aquest extensíssim escenari, el nazisme anirà desplegant les seves polítiques antisemites i exterministes, alimentades no només pel Mein Kampf, Julius Streicher i Alfred Rosenberg, sinó també per la llarga tradició de pogroms antisemites i de literatura i polítiques antijueves, provinent del món rus i dels seus veïns. Polonesos, russos, ucraïnesos, letons o lituans, van desfilant al costat dels perpetradors alemanys, austríacs i d'altres regions de l'Est europeu a l'hora de posar en pràctica les polítiques exterministes que culminaran en els camps de la mort, amb Auschwitz al capdavant.

En aquesta línia, el treball de Snyder recorda (i fa seva, en part) la llarga tradició de certa historiografia europea que va anar a buscar en les arrels culturals, nacionals o religioses alguns dels elements essencials amb què es construiria l'antisemitisme contemporani. En aquest sentit, les recerques i síntesis de Snyder ens porten fins a Norman Cohn i els seu treballs sobre la confecció i difusió dels Protocols dels savis de Sió. Per altra banda, complementa, enriqueix, acompanya en cert aspecte, la recerca capital de Raul Hilberg sobre la destrucció dels jueus. Ho podríem dir d'una altra manera: Snyder hauria de ser llegit abans de Hilberg, tot i haver estat escrit i editat molts anys més tard del'obra mestra de l'historiador austríaco-nord-americà.

No recomanaria llegir Tierras de sangre i, darrere, Tierra negra. Són dos treballs densos, carregats de dades i idees, que demanen una certa pausa i una mica de digestió. Però sí que els posaria en la biblioteca de treballs essencials, no sobre els genocides studies, sinó sobre l'Europa del segle xx i, encara més concretament, sobre una Europa determinada, aquella que arranca al cor del continent i s'estén fins a la frontera amb el continent asiàtic, on, molt més que als Balcans en les dites churchillianes, s'hi cou tanta història que es fa difícil digerir-la sense prendre mal.

Francesc Vilanova 